Indian Journal of Science and Technology

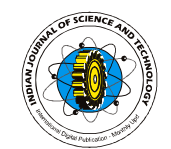

\title{
Monitoring of induction motor temperature under unbalanced supplying by stator resistance estimation
}

\author{
Masoud Sabaghi and Hassan Feshki Farahani \\ Department of Electrical Engineering, Ashtian Branch, Islamic Azad University, Ashtian, Iran \\ sab20022003@yahoo.com*
}

\begin{abstract}
Motor parameters estimations are needed for many applications. One of these parameters is stator winding resistance. Induction motor temperature can be monitored by this parameter estimation under balanced and unbalanced condition. For this purpose, a DC signal is injected to AC voltage. In this study, stator temperature is obtained from two methods. One of them is measuring by construction of a temperature measurement system using sensor-installing method and the other method is measuring temperature by Stator Winding Estimating (SWE). Each method is implemented on a $1.1 \mathrm{~kW} / 50 \mathrm{~Hz} / 1400 \mathrm{rpm}$ three-phase squirrel cage induction motor. After that, different experimental tests have been done on the motor under balanced and unbalanced conditions and they have been evaluated. The capability of measuring temperature from SWE method is investigated and responding of this method to motor thermal characteristics variations and reliable thermal protection are evaluated.
\end{abstract}

Keywords: Sensor Installing, DC Injection, Temperature Monitoring, Induction Motor and Stator Winding.

\section{Introduction}

Induction motors have many advantages which among them low cost, high reliability, low inertia and high transient torque capacity can be mentioned. In these motors, about $35 \%-45 \%$ of motor failures are caused by stator insulation breakdown. One of the operation, and situations where the cooling ability of the motor is accidentally reduced (Farag et al., 1994; Hurst \& Habetler, 1997).

Many papers are presented about thermal behavioral and modeling of induction motor (Mendes et al., 2008; Anwari \& Hiendro 2010; Bai, 2010; Yu et al., 2010; Valenzuela \& Ramírez 2011; Wrobel et al., 2011). Influence of unbalance factors on calculating total copper losses, efficiency, power factor, input power, output torque, peak currents, and de-rating factor of motor operating under unbalanced voltage system is evaluated in (Anwari \& Hiendro, 2010).

Reference (Mendes et al., 2008) describes a series of experimental tests that were conducted on a $4 \mathrm{~kW}$ total enclosed fan cooled (TEFC) three-phase induction motor. The tests were carried out when motor is supplied by both voltage source inverter and sinusoidal voltage source, considering the influence of the ventilation. A comprehensive transient temperature of both stator and rotor is presented. The 3-D temperature rise of induction motor is analyzed and computed using finite element method in (Bai et al., 2010). In this paper, heat resource of motor, equivalent coefficient of heat conductivity for the stator coil, and coefficient of heat convection in the airgap are analyzed. Furthermore, the temperature distribution of motor is simulated and results are analyzed. The influences of broken bars located at different relative positions on an induction motor are presented by Ying (2010). In this investigation, a finiteelement model of the squirrel-cage induction motor is developed. Valenzuela and Ramírez (2011) valuated three thermal models that are capable of detecting effects of pulp on dissipation of operating losses to the ambient. Thermal analysis of a segmented stator winding design is presented by Wrobel et al. (2011). This approach allows for a rapid and inexpensive assessment of thermal performance of the complete machine and early identification of design modifications needed.

In this paper, DC injection method is used for estimation of stator winding resistance for temperature monitoring of induction motor under unbalanced supplying condition. The stator temperature is obtained using two methods, which are temperature measurement with sensor installing method and DC injection method. Each method is implemented on a $1.1 \mathrm{~kW} / 50 \mathrm{~Hz} / 1400 \mathrm{rpm}$ three-phase squirrel cage induction motor. To verify DC injection method efficiency, different tests are carried out under unbalance condition.

Table 1. Resistance measurement and estimation or motor temperature using resistance

\begin{tabular}{|c|c|c|c|c|c|c|c|c|c|c|c|c|c|}
\hline Time [Min] & $\mathbf{1}$ & $\mathbf{5}$ & $\mathbf{1 0}$ & $\mathbf{1 5}$ & $\mathbf{2 0}$ & $\mathbf{2 5}$ & $\mathbf{3 0}$ & $\mathbf{3 5}$ & $\mathbf{4 0}$ & $\mathbf{4 5}$ & $\mathbf{5 0}$ & $\mathbf{5 5}$ & $\mathbf{6 0}$ \\
\hline Voltage [V] & 12.15 & 12.34 & 12.52 & 12.57 & 12.64 & 12.61 & 12.56 & 12.65 & 12.77 & 12.86 & 12.88 & 12.90 & 12.98 \\
\hline Current[A] & 4.02 & 3.98 & 3.98 & 3.99 & 3.99 & 3.97 & 3.94 & 3.94 & 3.95 & 3.95 & 3.93 & 3.93 & 3.92 \\
\hline $\begin{array}{c}\text { Winding } \\
\text { Resistance } \\
{[\Omega]}\end{array}$ & 3.02 & 3.1 & 3.14 & 3.15 & 3.17 & 3.18 & 3.19 & 3.21 & 3.23 & 3.25 & 3.28 & 3.29 & 3.31 \\
\hline $\begin{array}{c}\text { Measured } \\
\text { Temp [ }\end{array}$ & 30 & 34 & 37 & 38 & 40 & 41 & 42 & 44 & 45 & 45 & 50 & 55 & 60 \\
\hline $\left.\begin{array}{c}\text { Estimated } \\
\text { Temp [ }\end{array}{ }^{\mathrm{C}} \mathrm{c}\right]$ & 30.2 & 36.6 & 40.4 & 40.8 & 42.2 & 42.9 & 43.9 & 45.7 & 47.6 & 12.86 & 12.88 & 12.90 & 12.98 \\
\hline
\end{tabular}

Research article

COIndian Society for Education and Environment (iSee)
"Monitoring the induction motor temperature" http://www.indjst.org
M.Sabaghi \& H.F.Farahani Indian J.Sci.Technol. 
Estimation of inductive motor temperature by measuring its resistance

By connecting one of phases of 3- $\Phi$ squirrel-cage induction motor windings to DC power supply and increasing current value to $4 \mathrm{~A}$, winding voltage and current can be measured. Also, a digital temperature sensor with $1^{\circ} \mathrm{C}$ accuracy has been installed in this winding to measure its temperature. A delicate voltmeter and ampere meter are also used to measure winding voltage and current.

Examination goal is to determine motor winding resistance variations and to estimate its temperature as well. Circuit voltage and current values which are measured for one hour (each $5 \mathrm{~min}$ ) and winding temperature values (determined by sensor) are listed in Table.1.

In another row of this table, estimated temperatures are shown which are obtained by replacing resistance in equation $\Delta R / \Delta T=\alpha_{\text {cu }} R_{0}$ which

$\alpha_{\text {cu }}=0.004 \mathrm{~K}^{-1}$.

Stator resistance increases due to temperature increase (Fig. 1). Both measured and estimated temperatures are compared (Fig. 2). The estimated temperature values are approximately close to measured ones. In this investigation due to using DC voltage and current, resistance calculation becomes simple; however, motor works by $A C$ voltage supply. A question that may arise here is how motor winding resistance can be determined while the motor works by AC power supply. The answer is that a DC component should be added to motor voltage. As a result, similar to previous examination, a DC current will be generated in motor. Then by computing ratio of DC voltage to DC current, motor resistance will be determined. For this purpose, a DC injective system should be placed in motor basic circuit supply. How to locate this DC injector is shown in Fig. 3.

\section{$D C$ injector circuit}

DC injector circuit is composed of a resistance $\left(R_{\text {ext }}\right)$ and a MOSFET switch as shown in Fig. 4 . If the switch is turn on, in positive cycle, most of $\mathrm{I}_{2}$ flows through switch and in negative cycle, all $I_{3}$ flows through MOSFET internal diode. When switch is turn off, $l_{1}$ in positive and negative cycles flows through MOSFET resistance and diode respectively, consequently, when switch is turn on, resistance is one of motor phases is parallel with $R_{d s, o n}$, $R_{\text {ext }}$ resistances. Because of small value of $R_{d s, o n}$ resistance while MOSFET is turn on , three-phase current flows in motor.

Now, if switch is turn off, $R_{\text {ext }}$ in positive cycle and diode resistance (very low) is series with one of the motor phases. Therefore, current amplitude in positive cycle is smaller than that in negative cycle. From current waveform in Fig. 5, it can be realized that a DC component have been added to it and switch voltage will also contain DC component. Motor equivalent resistance value can be obtained by current and voltage values. This resistance is:

$$
\mathrm{R}_{\mathrm{s}}=\frac{2}{3} \frac{\mathrm{V}_{\mathrm{dc}}}{\mathrm{I}_{\mathrm{dc}}}
$$

Total Structure of stator resistance estimator system is practically implemented which is illustrated in Fig. 6 . System operation is divided into two parts: DC injection and normal parts. In former case (DC injection), system is operated in a way that processor sends turning off signal to MOSFET driver. As it was stated before, by turning off MOSFET, current amplitude in positive cycle will be less than its negative amplitude due to $R_{\text {ext }}$ resistance. In other words, there will be a DC component in switch voltage. At this time, processor reads switch voltage and current by $A / D$ converter and after some calculations; it sends this information to computer by RS232 port in order to temperature monitoring process.

In latter part (normal case), turning-on signal is sent to MOSFET by processor. When MOSFET is activated, its voltage drop is insignificant due to subtle resistance value. Therefore, DC injection mode does not exist in this case. To decrease losses in switch circuit and induction motor winding, injection time is much more less than normal mode time. Here, normal time according to load type is considered each 5 minutes. Also, injection time is considered about 15 cycles of grid voltage (about 300 $\mathrm{m} / \mathrm{sec}$ ). For heavy loads, motor resistance sampling should be carried out in shorter period of time (for instance every second) because of rapidly increasing motor temperature. In light loads, normal case is about every 10 minutes. Different parts of circuit are described in following sections.

Table 2. Motor resistance estimation under no load condition

\begin{tabular}{|c|c|c|c|c|c|c|c|c|c|c|c|c|c|}
\hline Time [Min] & 1 & $\mathbf{5}$ & 10 & 15 & 20 & 25 & 30 & 35 & $\mathbf{4 0}$ & $\mathbf{4 5}$ & 50 & 55 & 60 \\
\hline $\begin{array}{c}\text { Estimated } \\
\text { Resistance } \\
{[\Omega]}\end{array}$ & 2.99 & 3.00 & 3.02 & 3.04 & 3.03 & 3.03 & 3.04 & 3.03 & 3.05 & 3.04 & 3.05 & 3.07 & 3.09 \\
\hline $\begin{array}{c}\text { Sensor } \\
\text { Temp [ }\end{array}$ & 25 & 26 & 26 & 27 & 28 & 28 & 29 & 29 & 30 & 30 & 30 & 31 & 31 \\
\hline $\begin{array}{c}\text { Estimated } \\
\text { Temp [ }\end{array}$ & 24.5 & 25.6 & 27.3 & 28.2 & 27.7 & 28.1 & 28.6 & 27.9 & 29.2 & 28.7 & 29.3 & 31.3 & 32.5 \\
\hline Error [ $\left.{ }^{\circ} \mathrm{C}\right]$ & -0.5 & -0.4 & +1.3 & +1.2 & -0.3 & +0.1 & +0.4 & -1.1 & -0.8 & -1.3 & -0.7 & +1.3 & +1.5 \\
\hline
\end{tabular}

Research article

COIndian Society for Education and Environment (iSee)
"Monitoring the induction motor temperature" http://www.indjst.org
M.Sabaghi \& H.F.Farahani Indian J.Sci.Technol. 


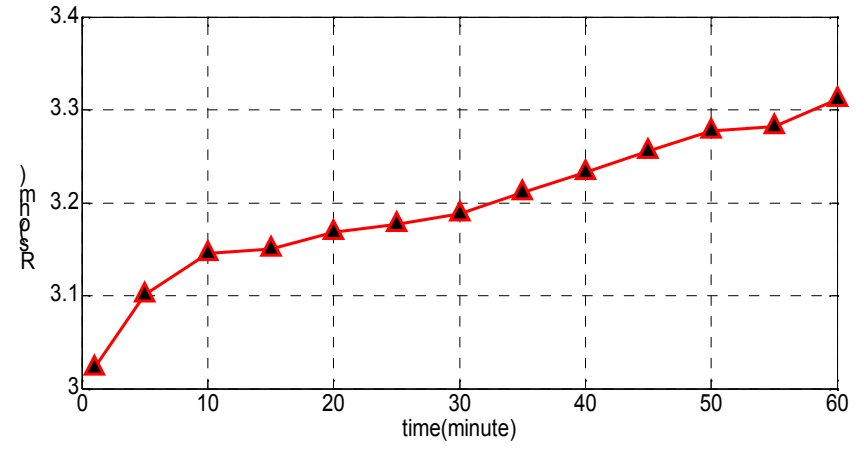

Fig. 1. Stator resistance increasing due to temperature increasing for one hours

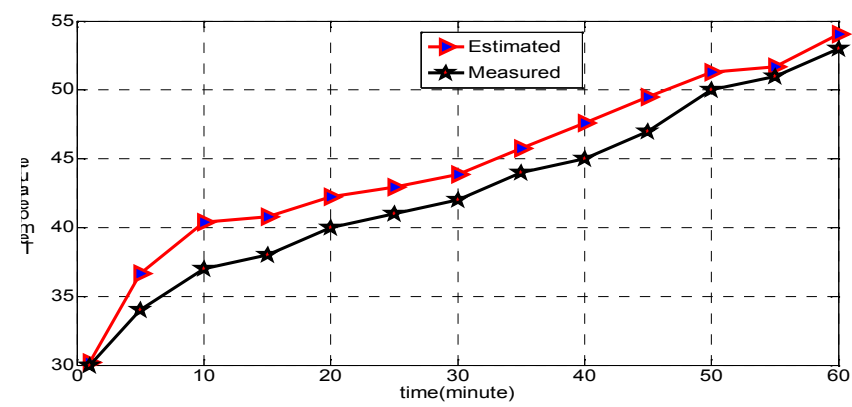

Fig. 2. Measured and estimated temperature of stator

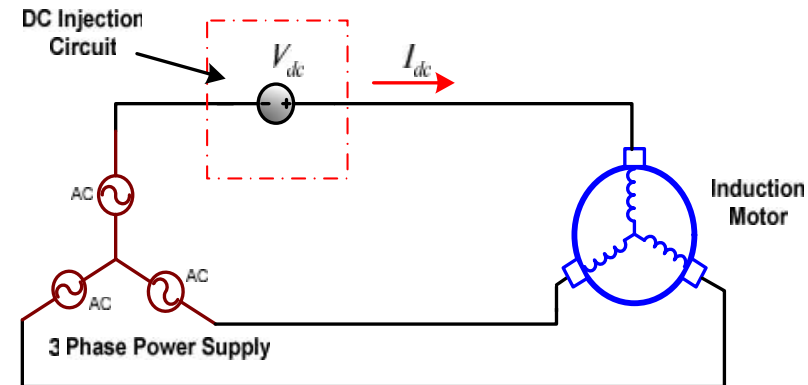

Fig.3. Location of DC injection circuit between motor and supply (Lee and Habetler 2003)

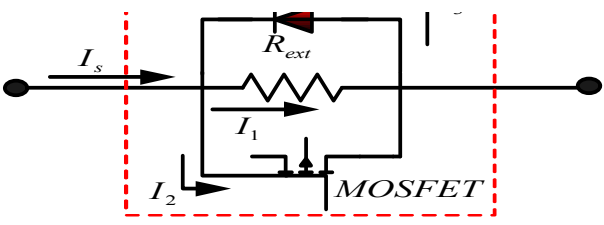

Fig.4. DC injector circuit (Lee and Habetler 2003)

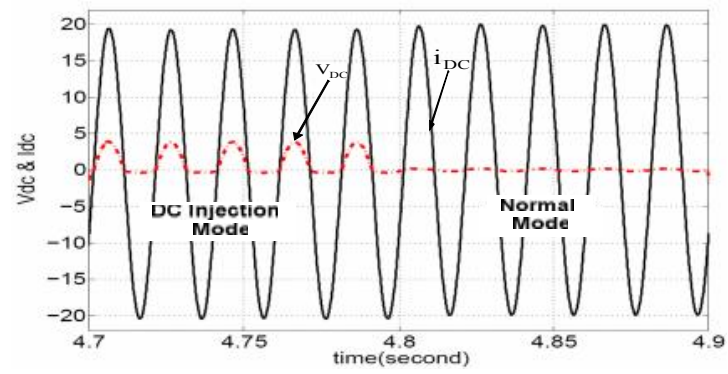

Fig.5. Waveforms of $V_{D C}$ and $i_{D C}$ under $D C$ injection mode and normal mode

Research article

Clndian Society for Education and Environment (iSee)

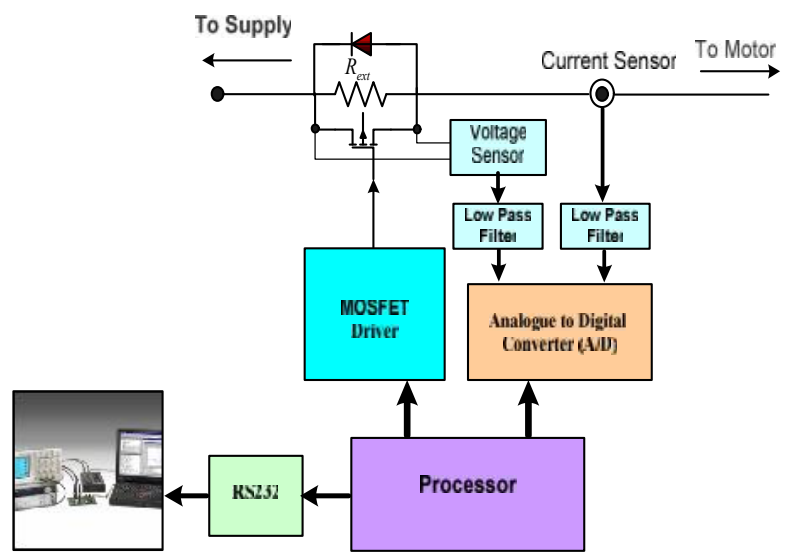

Fig.6. Structure of stator resistance estimator

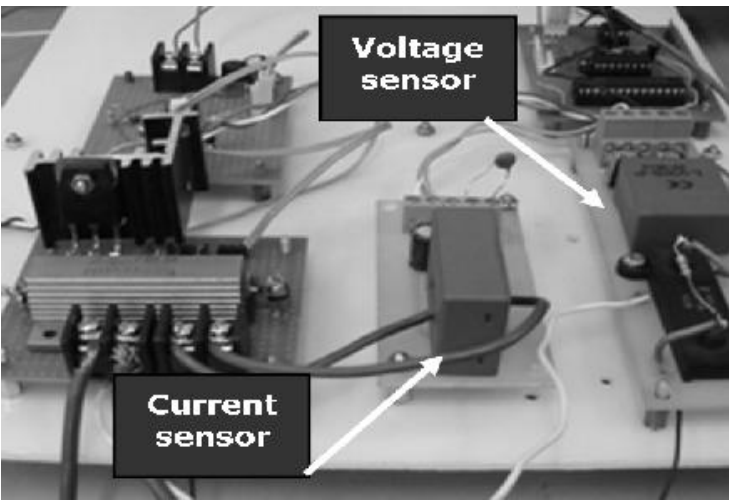

Fig. 7. General monitoring system of motor temperature using sensor installation method

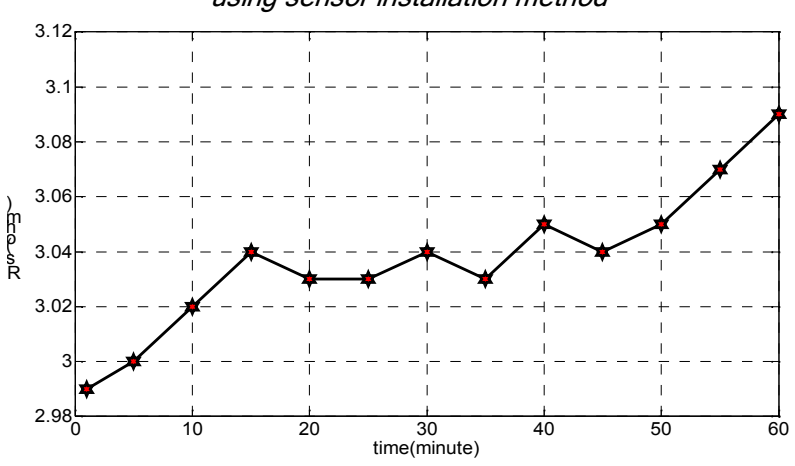

Fig.8. Estimation of stator resistance using DC injection method in no-load condition

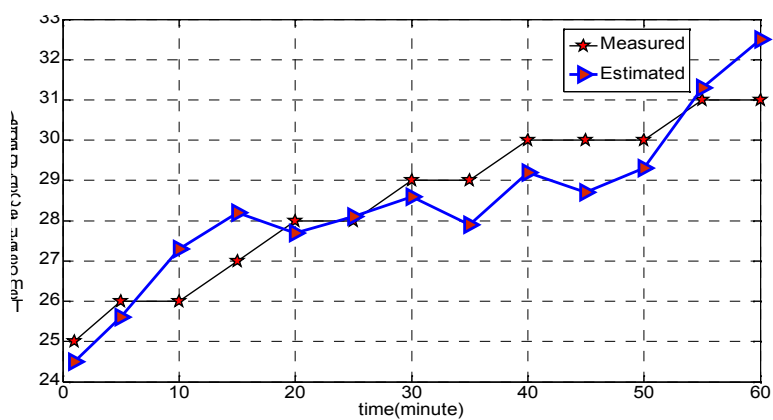

Fig.9. Stator temperature obtained from measured and estimated method in no-load condition
"Monitoring the induction motor temperature" http://www.indjst.org
M.Sabaghi \& H.F.Farahani Indian J.Sci.Technol. 
Indian Journal of Science and Technology

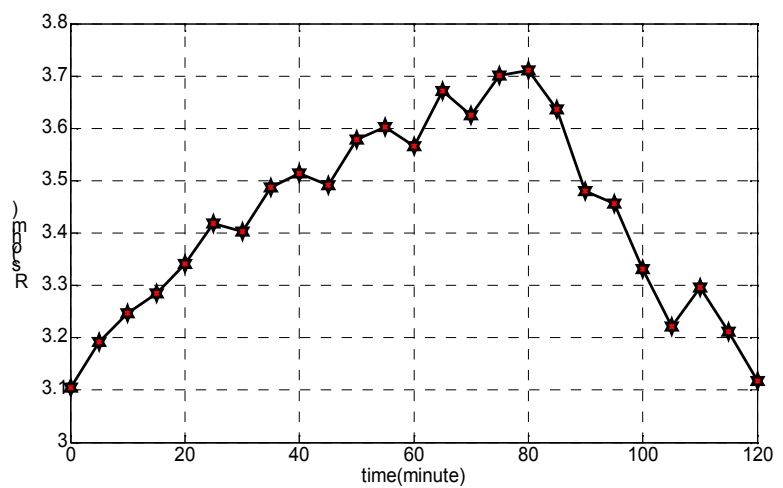

Fig. 10. Estimation of stator resistance under locked-

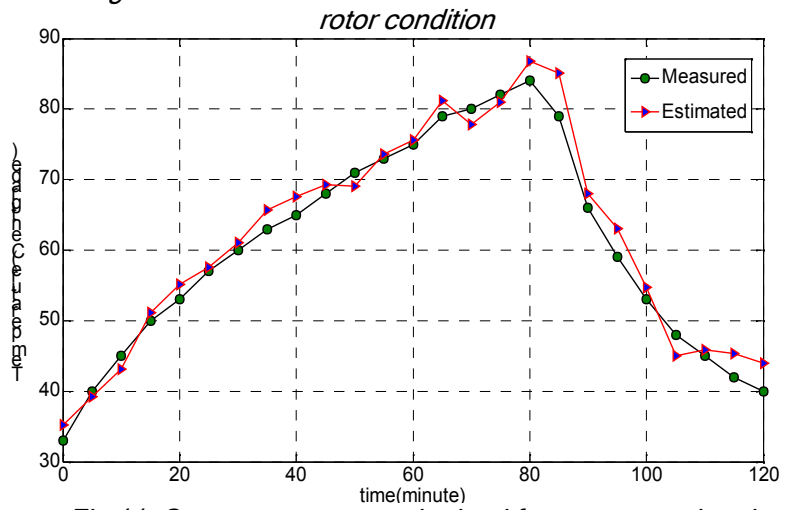

Fig 11. Stator temperature obtained from measured and estimated method under no-load and locked rotor

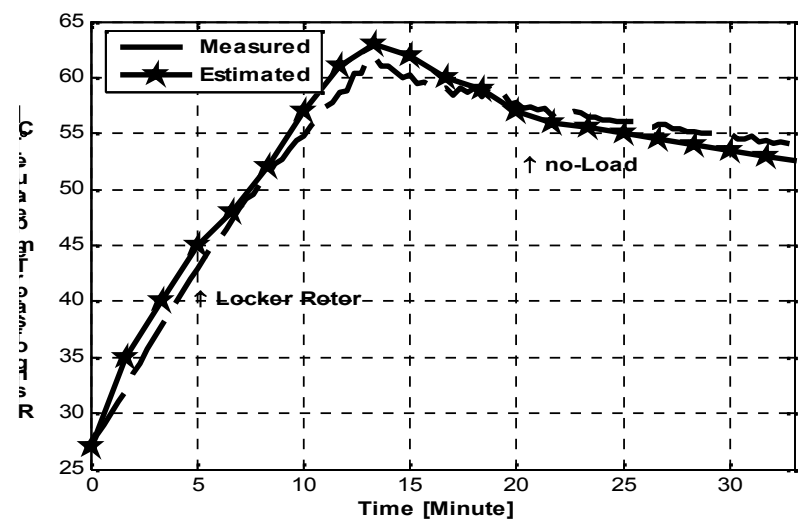

Fig 12. Stator temperature obtained from measured and estimated method with balance supplying in the increasing interval and balance supplying decreasing interval
Vol. 5 No. 3 (Mar 2012)

ISSN: 0974- 6846

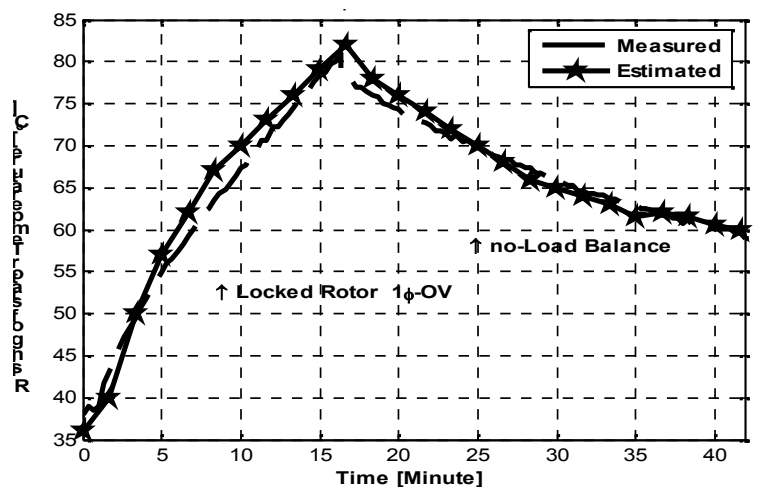

Fig 13. Stator temperature obtained from measured and estimated method with unbalance supplying in the increasing interval and balance supplying decreasing interval

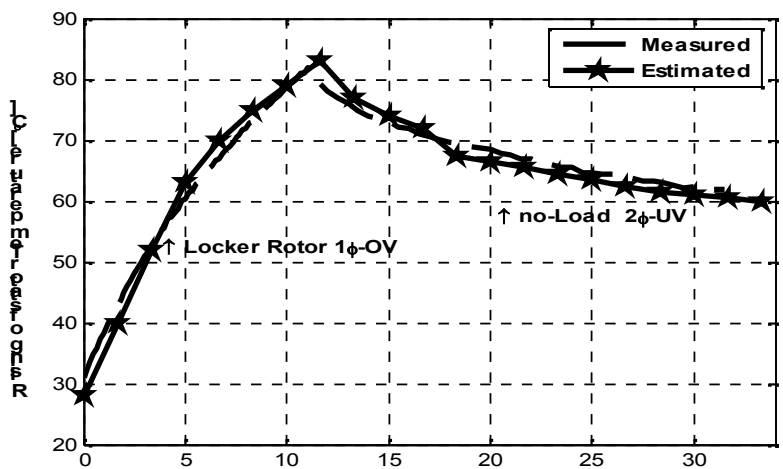

Fig 14. Stator temperature obtained from measured and estimated method with unbalance supplying in the increasing and decreasing interval

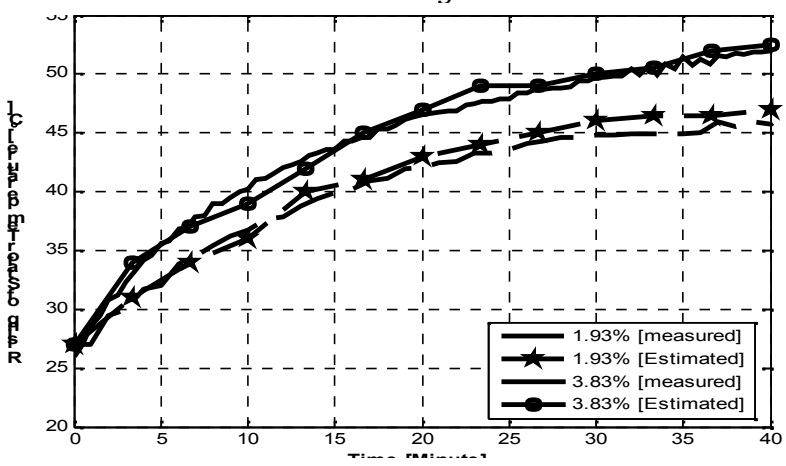

Fig 15. Stator temperature obtained from measured and estimated method in no-load with different unbalance supplying $[2 \varphi-U V]$

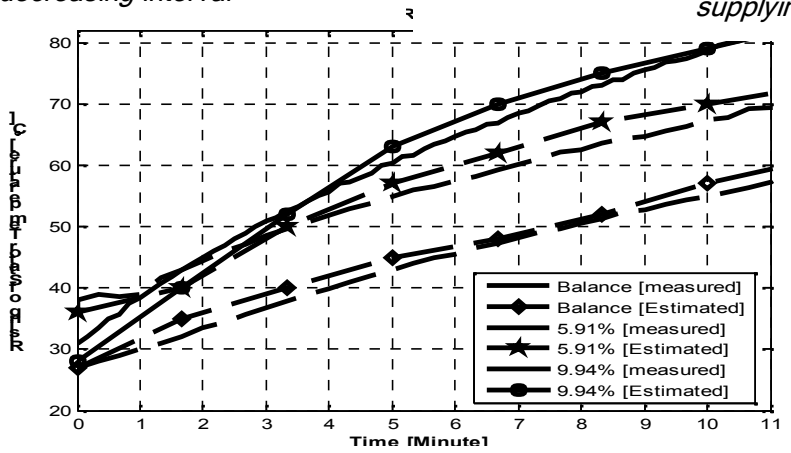

Fig 16. Stator temperature obtained from measured and estimated method in no-load with different unbalance supplying [1 $\varphi$-OV]

Research article

COIndian Society for Education and Environment (iSee)
"Monitoring the induction motor temperature" http://www.indjst.org
M.Sabaghi \& H.F.Farahani Indian J.Sci.Technol. 


\section{Experimental results}

After implementation this system, some experiments have been carried out on squirrel cage induction motor to verify system efficient operation. Digital sensors of STM160 are installed in winding of each phase. Then, temperature estimated by this system is compared with that estimated by installed sensors in stator; Resistance of each phase is $3.02 \Omega$ at room temperature. This system is shown in Fig. 7 which consists of induction motor, DC generator and resistance estimator system.

\section{No-load experiment}

In this experiment, phase voltage is $229 \mathrm{~V} / 50 \mathrm{~Hz}$. Noload current for each phase is considered 0.86 and angular speed is determined about $2900 \mathrm{rpm}$. Due to low thermal losses and consequently slow temperature increasing process, sampling has been done every $5 \mathrm{~min}$.

Estimated resistance by switch and calculated temperature by sensor are listed in Table. 2. Resistance increasing curve is plotted in Fig. 8. Estimated and calculated temperature values have been compared and results are illustrated in Fig. 9. As it is obvious from obtained results, the maximum error of measured values is $1.5^{\circ} \mathrm{C}$.

\section{Locked-rotor experiment}

This experiment has been considered in locked-rotor condition. Motor phase voltage is $40 \mathrm{~V}$ and its phase current is $3 \mathrm{~A}$. Resistance and sensor temperatures sampling is done every 5 minutes. After 80 minutes, to cool the motor, it is changed to no-load condition.

In this case, motor current is calculated $0.87 \mathrm{~A}$. In Fig. 10, estimated resistance curve and in Fig. 11, comparing results of measured and estimated temperatures are shown. According to these figures, up to 80 minutes, because of high motor current value, resistance estimation is better.

Investigation of voltage unbalancing effects on motor temperature

Different experiments have been accomplished to investigate different parameters effects on motor increasing temperature which some of them are mentioned in this paper.

Experiments are in two balanced and unbalanced voltage supplying conditions and include locked-rotor and no-load conditions. In locked-rotor case, motor drown nominal current from power supply. Nominal current is 3
A, 380V $1.1 \mathrm{~kW}$ and $140 \mathrm{rpm}$. These tested characteristics are listed in Table. 3. Unbalancing percentage has been defined in various ways among which definitions of NEMA and IEC are most important. In NEMA standard, unbalancing percentage is defined as follow:

$$
\text { Voltage Unbalance }=\frac{\Delta V_{\max }}{V_{\text {avg }}} \times 100 \text { (2) }
$$

Where $\mathrm{V}_{\text {avg }}$ is average voltage and $\Delta \mathrm{V}_{\max }$ is maximum difference between line voltage and average voltage. Voltage unbalanced definition presented by IEC standard is as follow:

$$
V U F=\left|\frac{V_{n}}{V_{p}}\right| \times 100 \text { (3) }
$$

Where $V_{n}$ is negative sequence voltage and $V_{p}$ is positive sequence voltage. Different tests have been carried out to investigate voltage unbalancing effects on motor temperature.

\section{First test}

Stator temperature using both methods under balance supply condition is shown in Fig. 12. Regarding of this figure, in temperature rising interval motor works under locked-rotor condition and stator temperature starts to increase. After 12 minutes, stator temperature reaches to $60{ }^{\circ} \mathrm{C}$.

After this time, motor is fed from balance supply in noload case and stator temperature begins to decrease. Also, this figure shows that motor temperature can be determined relatively accurate by estimation of stator winding resistance.

\section{Second test}

In this test, motor characteristics is $1 \Phi-\mathrm{OV}$ unbalance supply with unbalance percentage of $9.94 \%$ (VUF=9.94\%). Motor starts to work in locked-rotor condition and its temperature is increasing and after 15 $\mathrm{min}$, it reaches to $82^{\circ} \mathrm{C}$. After that, motor works in balance and no-load condition and its temperature is approximately equal to calculated temperature. For this condition, temperature variation is plotted in Fig. 13 .

\section{Third test}

In this test, motor works under these conditions: unbalance power supply, $1 \Phi-\mathrm{OV}$ with $\mathrm{VUF}=5 / 91 \%$ and

\begin{tabular}{|c|c|c|c|c|c|c|c|c|c|}
\hline case & $\mathrm{V}_{\mathrm{CA}}$ [Volt] & $\mathrm{V}_{\mathrm{BC}}$ [Volt] & $\mathrm{V}_{\mathrm{AB}}$ [Volt] & $V_{p}$ & $V_{n}$ & $\mathrm{~V}_{0}$ & $\operatorname{VUF}(\%)$ & Temperature & condition \\
\hline $1 \varphi-O V$ & 90 & 106 & 88.5 & 94.83 & 5.6 & 5.6 & 5.91 & Rising & LR \\
\hline $2 \varphi-U V$ & 351 & 370 & 348 & 356.33 & 6.89 & 6.89 & 1.93 & Rising & $\mathrm{nL}$ \\
\hline $1 \varphi-U V$ & 86 & 46 & 86 & 72.67 & 13.33 & 13.33 & 18.35 & Rising & LR \\
\hline $1 \varphi-O V$ & 100 & 131 & 97 & 109.33 & 10.87 & 10.87 & 9.94 & Rising & LR \\
\hline $2 \varphi-O V$ & 405 & 372 & 411 & 396 & 12.12 & 12.12 & 3.06 & Rising & $\mathrm{nL}$ \\
\hline
\end{tabular}

Table 3. The property of supplying voltage and motor operational condition (LR: Locked Rotor and nL: no-Load) 
locked-rotor condition. At first, motor temperature is increasing and it reaches to $83^{\circ} \mathrm{C}$ after $12 \mathrm{~m}$. after this time, motor starts working under unbalance, 2Ф-UV with VUF $=1.93 \%$ in no-load condition. Motor temperature is decreasing which is shown in Fig. 14.

Investigation of voltage unbalance impact on motor temperature decreasing

To investigate voltage unbalance influence on motor temperature, different tests have been conducted which are explained in following parts:

Motor temperature increasing in $2 \Phi-U V$ for no load condition

In this experiment, two unbalancing cases of VUF $=1.93 \%$ and $3.83 \%$ and $2 \Phi-U V$ have been tested in noload condition.

According to results shown in Table 3 , for each unbalancing, negative and zero sequence amplitude is equal to $6.89 \mathrm{~V}$ and $13 \mathrm{~V}$ respectively which are expected that these components cause motor temperature increasing. For this test, motor temperature obtained from both methods and for each unbalancing is plotted in Fig. 15. It shows that estimated results are approximately equal to calculated values.

Unbalance $1 \Phi-\mathrm{OV}$ on motor temperature increasing in locked rotor condition

In this investigation, three cases of balance, VUF = $5.91 \%$ and $\mathrm{VUF}=9.44 \%$ in $1 \Phi-\mathrm{OV}$ for a motor are considered in locked rotor condition. As it is shown in Fig. 16 , by increasing VUF, negative and zero sequence amplitude are increased which leads to motor temperature rising

\section{Conclusions}

In this paper, the stator temperature has been measured by estimation of stator winding resistance of induction motor under unbalance supplying condition. For this purpose, a DC signal injected to $A C$ voltage and the resistance of stator winding has been estimated under balanced and unbalanced conditions. The stator temperature has been obtained by construction of a temperature measurement system with sensor installing method. Each method has been implemented on a $1.1 \mathrm{~kW} / 50 \mathrm{~Hz} / 1400 \mathrm{rpm}$ three-phase squirrel cage induction motor and experimental results have shown that by using DC injection method, stator winding resistance (temperature) can be estimated with high accuracy. Also, experimental results have indicated that increase of motor temperature depends on the positive, negative and zero sequence voltage. In the high percent of unbalancing, the motor temperature increases due to positive voltage sequence reduction.
Vol. 5 No. 3 (Mar 2012)

ISSN: 0974- 6846

\section{References}

1. Anwari M and A Hiendro (2010) New Unbalance Factor for Estimating Performance of a Three-Phase Induction Motor With Under- and Overvoltage Unbalance. Energy Conversion, IEEE transactions. 25, (3)619-625

2. Bai B, Yu Q et al. (2010) 3-D Thermal analysis and computation of flameproof induction motor. Power \& Energy Engin. Conf. (APPEEC). 1-4.

3. Farag SF, Bartheld RG et al. (1994) Electronically enhanced low voltage motor protection and control. IEEE Trans. Industrial. Appl. 30, 776-784.

4. Hurst KD and Habetler TG (1997) Thermal monitoring and parameter tuning scheme for induction machines. In: Conf. Rec. IEEE-IAS Annu. Meeting 1, 136-142.

5. Lee SB and Habetler TG (2003) An online stator winding resistance estimation technique for temperature monitoring of line- connected induction machines. IEEE Trans. Industrial. Appl. 39 (3).

6. Mendes AMS, XM LF et al (2008) Thermal evaluation of TEFC three-phase induction motors under different supply frequencies. Electrical Machines, ICEM 2008. 18th Int. Conf. 1-6.

7. Valenzuela MA and Ramírez G (2011) Thermal models for online detection of pulp obstructing the cooling system of TEFC induction motors in pulp area. IEEE Trans. Industrial. Appl. 47, 719-729.

8. Wrobel RP, Mellor $\mathrm{H}$ et al. (2011) Thermal modeling of a segmented stator winding design. IEEE Trans. Industrial. Appl. 47(5), 2023-2030.

9. Ying $X$ (2010) Performance evaluation and thermal fields analysis of induction motor with broken rotor bars located at different relative positions. IEEE Transact. Magnetics. 46, 1243-1250.
"Monitoring the induction motor temperature" http://www.indjst.org
M.Sabaghi \& H.F.Farahani Indian J.Sci.Technol. 